\title{
Desafios no ensino e aprendizagem de línguas adicionais para crianças em tempos de covid-19: vozes de professoras de um contexto mato-grossense
}

\section{Challenges in teaching and learning additional languages for children in covid-19 time: voices of teachers in a}

Mato Grosso context

\author{
Vitória França Albuquerque \\ Universidade do Estado do Mato Grosso - UNEMAT - Mato Grosso - Brasil
}

\section{Riscieli Dallagnol(i)}

Universidade do Estado do Mato Grosso - UNEMAT - Mato Grosso - Brasil

\section{Leandro Ines Seganfredo Santos}

Universidade do Estado do Mato Grosso - UNEMAT - Mato Grosso - Brasil

\begin{abstract}
Resumo: O estudo apresenta os resultados de uma pesquisa realizada com professoras de línguas adicionais para crianças, de um contexto mato-grossense, com o intuito de compreender os desafios enfrentados nesse momento de distanciamento social e as estratégias usadas para promover às crianças, na medida do possível, uma educação de qualidade social. O trabalho pauta-se nos pressupostos da Linguística Aplicada e discute os conceitos de línguas adicionais (SCHLATTER; GARCEZ, 2009) para crianças (SANTOS, 2009, 2005), tecnologias digitais e os desafios no ensino de línguas na pandemia (MENDONÇA, 2020), e insere-se no método de pesquisa qualitativa, de cunho interpretativista, baseada em Bauer, Gaskell e Allum (2002) e Gil (2008). Para a geração de dados, realizou-se entrevistas semiestruturadas, por meio da ferramenta Whatsapp, com cinco professoras de uma especialização Lato Sensu, ofertada por uma universidade pública situada ao norte de Mato Grosso. Os dados da pesquisa sinalizam que as professoras têm vivenciado dias desgastantes e enfrentado alguns desafios, tais como: dificuldade de adaptação ao uso das ferramentas digitais, invasão de privacidade devido a todo momento receberem mensagens de pais e alunos, falta de internet e, principalmente, de material pedagógico para esse novo contexto. Além disso, afirmam que o ensino de uma língua para crianças exige o contato que as aulas remotas não podem ofertar. Por fim, pontuam que a educação nunca foi tão excludente, tendo em vista que a aprendizagem de seus pequenos aprendizes se encontra prejudicada e as lacunas apresentadas, possivelmente, não serão preenchidas.
\end{abstract}

Palavras-chave: Línguas Adicionais para crianças. Desafios. COVID-19.

Abstract: The study presents the results of a survey conducted with additional language teachers for children in a Mato Grosso context in order to understand the challenges faced at this time of social distancing and the strategies used to promote children, as far as possible, an education of social quality. The work is based on the assumptions of Applied Linguistics and discusses the concepts of additional languages (SCHLATTER; GARCEZ, 2009) for children (SANTOS, 2009, 2005), digital technologies and the challenges in language teaching in the pandemic (MENDONÇA, 2020), and is part of the qualitative research method based on Bauer, Gaskell and Allum (2002), among others. For data generation, semi-structured interviews were conducted using the Whatsapp tool, with five professors from a Lato Sensu specialization offered by a public university located in the north of Mato Grosso. The data from the survey show that the teachers have been experiencing stressful days and faced some challenges, such as: difficulty in adapting to the use of digital tools, invasion of privacy due to all the time receiving messages from parents and students, lack of internet and, mainly, pedagogical material for this new context. In addition, they state that teaching a language to children requires the contact that remote classes cannot offer. Finally, they point out that education has never been so exclusive, considering that the learning of their small learners is impaired and the gaps presented, possibly, will not be filled.

Keywords: Additional Languages. Challenges. COVID-19 


\section{Introdução}

A pandemia da COVID-19 tem provocado significativas mudanças nas práticas sociais. No que se refere à educação, em específico, ao ensino de línguas adicionais para crianças, novas práticas de ensino têm surgido em atenção à atual conjuntura.

Nesse sentido, os objetivos deste estudo, a partir dos pressupostos teóricos da Linguística Aplicada, consistem em investigar os principais desafios enfrentados por professoras de línguas adicionais para crianças (doravante LAC) acerca do uso das tecnologias digitais e materiais utilizados em contexto de aulas remotas, durante a pandemia da COVID-19, com vistas à compreensão das estratégias que utilizam para promoção de uma educação de qualidade social às crianças, na medida do possível. Realizou-se, também, um levantamento bibliográfico a fim de compreender aspectos sobre a temática, identificar, por meio de entrevistas, quais as práticas formativas no tocante ao uso das tecnologias digitais as professoras realizaram para atender esse momento de distanciamento social e mapear as ferramentas digitais e materiais utilizados para a mediação do processo de ensino e aprendizagem.

Assim, a pergunta que direcionou a pesquisa foi: Quais os principais desafios enfrentados por professoras de línguas adicionais para crianças em relação ao uso das tecnologias digitais e materiais utilizados em contexto de aulas remotas, durante a pandemia da COVID-19?

Para responder ao questionamento e alcançar os objetivos propostos, esta pesquisa inscreve-se nos princípios do método de pesquisa qualitativa, de cunho interpretativista, baseado em Bauer, Gaskell e Allum (2002), dentre outros. A produção dos dados ocorreu mediante a realização de entrevistas semiestruturadas por meio da ferramenta WhatsApp, tendo em vista que o contexto atual requer o distanciamento social, o que dificulta o contato físico com as docentes.

O interesse por esse tema justifica-se pelo fato de ser um fenômeno social relativamente novo e seus efeitos são visíveis em vários âmbitos da sociedade, dentre os quais a Educação é um deles. Dessa forma, realizar uma pesquisa de tal abordagem é de grande importância para a área de formação docente, tendo em vista que a problemática apontada, neste estudo, será discutida e analisada por meio da visão de profissionais que ora vivenciam essa realidade: os professores.

Além desta introdução, apresenta-se, a seguir, a seção acerca dos pressupostos teóricos que fundamentam o estudo. Expõe-se também uma seção sobre os processos metodológicos, na qual é contextualizada a natureza do estudo, bem como, os sujeitos, o instrumento utilizado para a geração de dados e os critérios de análise. $\mathrm{Na}$ seção de resultados, apresenta-se os dados produzidos por meio de entrevistas, em que se analisa os desafios enfrentados por professoras de línguas adicionais para crianças em tempos de distanciamento social.

2. A sala de aula no mundo digital: perspectivas e desafios da formação docente no ensino de LAC em advento de pandemia

\subsection{Tecnologias digitais e formação docente}

Devido ao isolamento social decorrente da pandemia da COVID-19, as pessoas passaram a usar as tecnologias digitais com mais intensidade. A Organização Mundial de Saúde (OMS) declarou no começo de 2020 orientações para o combate ao coronavírus. No que diz respeito ao campo da educação, o Ministério da Educação - MEC - publicou, no Diário Oficial da União, Portaria No. 343/2020 (BRASIL, 2020), que autorizou o ensino emergencial remoto, o que causou nos profissionais da educação uma série de inquietações, tendo em vista as implicações dessa modalidade de ensino.

Apesar das tecnologias digitais já fazerem parte do cotidiano escolar, muitos professores, e também alunos, na atualidade, ainda têm dificuldades em usálas para fins educacionais. Pensar o seu uso por esses indivíduos, não é uma questão inédita, mas, com a crise sanitária, esses e outros aspectos ganharam certo destaque. Hoje, com mais força, as tecnologias digitais rompem barreiras físicas e geográficas, como se não existissem fronteiras e limites para a construção de conhecimento, isso contribui para que se tenha 
mudanças na formação de professores e, consequentemente, na aprendizagem dos alunos.

A pandemia desencadeou uma carga maior de utilização desses meios tecnológicos, assim, isso gera dificuldades, despreparo para lidar com esses recursos com tanta veemência. Outrossim, são tantas ferramentas existentes, que, às vezes, o professor não tem o letramento necessário para selecionar as que melhor se adequem ao seu contexto e de seus alunos. Entretanto, sabe-se que não é possível, pois muitos alunos também, apesar de viverem em uma cultura digital, não compartilham dessa mesma realidade.

De acordo com Liberalli (2020, p. 16), "Em momentos de crise, esse processo parece ficar ainda mais evidente quando as diferenças econômicas reforçam de forma repugnante as diferenças no acesso aos processos de ensino-aprendizagem". Essa realidade atual escancarou mais ainda as desigualdades sociais e econômicas, e um termo chamado de "necropolítica" (MBEMBE, 2016) parece se estender ao âmbito da educação com o que se pode nomear por "necroeducação" (LIBERALLI, 2020).

Em referência à formação docente, especificamente para esse momento, os professores encontram-se preocupados e, mesmo sem tempo hábil, buscam meios para se qualificarem e ministrarem suas aulas de modo significativo para que os alunos consigam acompanhar e realizar as atividades, na medida do possível. Assim, essa formação, tem ocorrido, principalmente, de forma autônoma, tendo em vista que as instituições formadoras apresentam, também, dificuldades em realizar momentos formativos para esse período emergente. (DIAS; PINTO, 2020).

Há, de certa forma, a cobrança no sentido de o professor dar conta de ensinar remotamente, sozinho e com os recursos que obtém, como se por detrás desse profissional não houvesse uma instituição maior, a qual também cabem as responsabilidades. Quando se fala nisso, refere-se se a sistemas governamentais, redes privadas, municipais, estaduais e federais, as próprias comunidades escolares devem ser os condutores desse processo. (MENDONÇA, 2020).
Nesse sentido, há a necessidade de uma formação inicial e continuada que prepare o professor para atuar em sua prática com o uso das tecnologias digitais de modo significativo, dado que "[...] em si, não constituem-se numa revolução metodológica nos processos educativo, mas certamente apresentam-se como possibilidades de contribuição para as novas configurações e reconfigurações dos processos de ensino e de aprendizagem" (FRIZON et al., 2015, p. 102002).

Essa formação promoverá subsídios para que o docente se aproprie do letramento digital, o qual é defendido por Lankshear e Knobel (2008), como um produto sociocultural e entendido como um conjunto de práticas sociais. A partir de um processo formativo em que a prática está materializada, o professor pode sentir-se mais tranquilo ao utilizar as tecnologias digitais em sala de aula. Além do mais, pode ter maiores possibilidades de desenvolver habilidades para averiguar as potencialidades dessas ferramentas no processo de ensino e aprendizagem, uma vez que as melhorias que ocorrem na formação de professores vêm das discussões acerca dessa área. (ALBUQUERQUE; SANTOS, 2020). Nesse sentido, Kenski (1998, p. 61) afirma "é chegado o momento em que nós, profissionais da educação, que temos o conhecimento e a informação como nossas matériasprimas, enfrentarmos os desafios oriundos das novas tecnologias."

\subsection{Desafios do ensino e da aprendizagem remotos de línguas adicionais para crianças durante a COVID-19}

Quando o assunto é ensinar línguas, um tema muito discutido é sobre as competências desejáveis para ser um bom docente. Nesse sentido, autores como Almeida Filho (2014; 2012), Santos (2009; 2005), entre outros, assumem preocupação com a formação desses profissionais e com o processo de ensino e aprendizagem.

Dessa forma, ensinar crianças é um trabalho que apresenta particularidades, o professor necessita ter algumas características defendidas por Santos 
(2009), tais como: domínio linguístico e teórico sobre a LA, fazer uso de metodologias ativas e atrativas, ter conhecimento sobre o desenvolvimento da criança, possuir o domínio do conteúdo para essa faixa etária e área, ser habilitado na língua que deseja atuar, gostar dessa língua, possuir vontade e ser dinâmico nas aulas e, principalmente, estar em constante evolução, ou seja, aperfeiçoar-se por meio de cursos, eventos.

As peculiaridades em relação ao desenvolvimento dos trabalhos com esse público já apresentavam dificuldades no quesito materiais pedagógicos. Enquanto os professores buscavam entender as problemáticas que envolvem essa área de atuação "relativamente nova e desafiadora" (AQUINO; TONELLI, 2017, p. 58), surgiu a pandemia da COVID19 e modificou sua prática pedagógica, como afirma Liberalli (2020, p.15) em que a "crise da covid-19, que suscita a criação do inédito viável, depende da forma como são acionados e desenvolvidos os patrimônios vivenciais de cada um em face das demandas impostas por essa realidade, é necessário potencializar os sujeitos."

A emergência do ensino remoto trouxe muitos desafios para o docente, tais como: cansaço, estresse e problemas emocionais no geral, falta de privacidade, trabalho em tempo integral, falta de interação social e acompanhamento das crianças por pais ou responsáveis, problemas com internet, falta de recursos necessários para assistir e ministrar aulas, materiais pedagógicos adequados, dentre outros.

No que se refere à questão da falta de materiais pedagógicos para o ensino de LAC, Aquino e Tonelli (2017, p. 58) afirmam que "existe uma escassez de materiais adequados para ensinar inglês para crianças e falta de parâmetros norteadores para selecionar e adaptar os materiais disponíveis, de maneira que atendam às necessidades de ensino-aprendizagem dos alunos adequadamente. Essa problemática é discutida também por Santos (2011; 2009; 2005), dentre outros.

É importante ressaltar que esse momento trouxe outros desafios ao professor, como por exemplo, adequar ou até mesmo produzir materiais autênticos com o uso de aplicativos ou plataformas para que as aulas possibilitem interações sociais. Se antes isso já era difícil, certamente ficou mais latente. Para que o ensino e aprendizagem de LAC obtenha sucesso, é necessário a interação com o professor e com os outros colegas, aspecto esse de fundamental importância para o desenvolvimento das crianças. (FIGUEIREDO, 2019; VYGOTKSY, 2007). Isto se torna quase impossível, haja vista que muitos alunos não têm acesso à internet, o que mostra que o ensino remoto não é para todos, como afirmam Megale e Nunes (2020, p. 171):
Se por um lado, temos escolas privadas com professores e alunos em condições tecnológicas e econômicas mínimas que possibilitam um ensino remoto, por outro, temos escolas públicas, nas quais parte considerável dos alunos não têm acesso a computadores e redes de internet, dentre diversos outros fatores que colocam o ensino remoto como uma solução inadequada e distante dessa realidade.

Ainda sobre a questão da interação, o feedback entre aluno e professor é direto e simultâneo na sala de aula física. Basta olhar ao redor para perceber se os alunos estão engajados, se a turma compreendeu que foi dito, proposto etc. Porém, no ensino remoto, na sala de aula virtual, não há como realizar esse acompanhamento.

Outro desafio que torna o trabalho do professor mais problemático diz respeito à ausência de acompanhamento às crianças por um adulto. Há todo um preparo e dedicação para produzir atividades significativas para o aluno nesse momento. Entretanto, não tem a segurança ou a certeza se vão recebê-las e realizadas, já que a grande maioria dos pais ou responsáveis não tem tempo para ajudar o estudante nas tarefas da escola, devido a estarem trabalhando em home office para garantir o sustento da família. (DIAS; PINTO, 2020). Ademais, é temeroso contar com o conhecimento linguístico dos pais na língua estudada. Essa situação tem se tornado um contratempo expressivo, já que os alunos precisam ser avaliados por essas atividades que são geralmente enviadas por WhatsApp de forma quase ilegível. No tocante a esse aspecto, Santos (2009) afirma que a avaliação de crianças pode ser um aspecto discutível se o professor considerar apenas a concepção dos métodos tradicionais, pois não possibilitam a visualização acerca do que as crianças realmente aprenderam. Sobre a questão do planejamento 
significativo, Dallagnol (2019) discorre sobre a importância do planejamento das aulas para que ocorra a aprendizagem efetiva dos alunos.

A falta de privacidade é um fenômeno compartilhado por todos os professores nesse momento. Não houve tempo para uma adequação como um todo de sua prática para o ensino remoto. Então, além de terem que lidar com a falta de tempo para a criação de material autêntico, recebem, praticamente o dia todo, mensagens em seu WhatsApp de pais e alunos para esclarecerem dúvidas ou realizarem perguntas.

Assim, no que se refere à situação no contexto de escolas privadas, Megale e Nunes (2020) discorrem que foram compelidas a assegurar o funcionamento das aulas, mesmo durante a pandemia, sob ameaças diversas de rompimento da relação dos pais com a escola. É nesse panorama que encontramos situações de "[...] assédio moral a professores que, de uma hora para outra, tiveram que lançar mão de recursos e habilidades, ainda não construídas, para lidar com o ensino a distância". (MEGALE; NUNES, 2020, p. 171). Entretanto, sabe-se que essa situação não é exclusiva do contexto privado, pois os professores da rede pública também experienciam os mesmos fenômenos e, em muitos casos, em situações menos privilegiadas.

Dessa forma, os professores não têm mais horário para começar e encerrar suas atividades docentes. $O$ trabalho começa logo nas primeiras horas do dia e se estende pela madrugada também. Certamente isso gera problemas emocionais que são aspectos que devem ser ouvidos durante esse momento turbulento, caso contrário, podem tornar o desenvolvimento das atividades docentes, e também discentes, inviáveis. (ARAGÃO; CAJAZEIRA 2017; BARCELOS; SILVA, 2015).

Defende-se que por mais problemas e mudanças que surjam na educação, nada vai substituir um bom professor, este profissional "continua como peça-chave para a educação. Um tanto desprestigiado, em busca da identidade profissional e sobrecarregado de culpa pelo fracasso escolar" (FERREIRA, 2015, p. 46), entretanto, seu papel é primordial na sociedade.

\section{Caminhos metodológicos}

\subsection{Natureza}

Para atingir os objetivos propostos, utilizou-se a metodologia de investigação aplicada, de cunho interpretativista cuja natureza inscreve-se no método de pesquisa qualitativa, baseado em Bauer, Gaskell e Allum (2002) e Gil (2008). Para os primeiros autores (2002, p. 30) a "pesquisa qualitativa é, muitas vezes, vista como uma maneira de dar poder ou dar voz às pessoas, em vez de tratá-las como objetos, cujo comportamento deve ser quantificado e estatisticamente modelado".

Essa metodologia possui caráter flexível e permite que o pesquisador olhe para o fenômeno investigado mediante a visão dos colaboradores da pesquisa. Além do mais, no momento da interação entre os sujeitos envolvidos no processo, outras questões podem emergir e serem abordadas para captar informações que poderão ser valiosas para o momento de análise de dados.

\subsection{Contexto de pesquisa e perfil das professoras colaboradoras}

O contexto de pesquisa diz respeito ao curso de especialização Lato Sensu em Ensino e Aprendizagem de Línguas Adicionais para Crianças. Essa pós-graduação, ofertada pela Universidade do Estado de Mato Grosso UNEMAT, foi uma ação institucionalizada do Grupo de Estudos e Pesquisas em Linguística Aplicada e Sociolinguística - GEPLIAS. Teve como objetivo oferecer aos profissionais interessados, seja de Letras, Pedagogia ou qualquer área do conhecimento que atuam na área ou tenham interesse em conhecer pressupostos teóricopráticos do ensino e aprendizagem de línguas adicionais para crianças. Os discentes eram provenientes de vários municípios de Mato Grosso.

Os sujeitos de pesquisa são professoras de línguas adicionais para crianças, atuantes em diferentes âmbitos de ensino e, no período de coleta de dados, estavam em fase de conclusão da especialização supracitada. Para preservar suas identidades, foram utilizadas palavras em que representam não apenas os desafios vivenciados pelas docentes nesse momento tão atípico, mas também as suas conquistas em se reinventarem. Os nomes fictícios são: Superação, Persistência, Afeto, Calma e Coragem. 


\begin{tabular}{|c|c|c|}
\hline $\begin{array}{l}\text { Identificação } \\
\text { dos sujeitos }\end{array}$ & Formação & Área de Atuação \\
\hline $\begin{array}{c}\text { Superação } \\
55 \text { anos }\end{array}$ & Letras/Português-Inglês & $\begin{array}{l}\text { Leciona inglês em uma escola da rede municipal de } \\
\text { ensino em Lucas do Rio Verde - MT para turmas de } 1^{\circ} \text { a } \\
4^{\circ} \text { anos do Ensino Fundamental I. }\end{array}$ \\
\hline $\begin{array}{c}\text { Persistências } \\
50 \text { anos }\end{array}$ & Letras/Português-Inglês & $\begin{array}{l}\text { Trabalha com ensino de língua inglesa para crianças } \\
\text { com idade de } 8 \text { a } 12 \text { anos, há cerca de } 8 \text { anos, quando } \\
\text { começou a trabalhar em um centro de idiomas em Sinop } \\
\text { - MT. Atualmente, também leciona na rede estadual de } \\
\text { ensino público, mas com alunos de faixa etária maior }\end{array}$ \\
\hline $\begin{array}{c}\text { Afeto } \\
48 \text { anos }\end{array}$ & Letras/Português-Inglês & $\begin{array}{l}\text { Atua com língua Inglesa para crianças há } 13 \text { anos em } \\
\text { escola de idiomas com crianças a partir de } 4 \text { anos até } 7 \\
\text { anos. Atualmente, é professora e coordenadora de uma } \\
\text { filial de um centro de idiomas em Lucas do Rio Verde. }\end{array}$ \\
\hline $\begin{array}{l}\text { Calma } \\
29 \text { anos }\end{array}$ & Letras/Português-Inglês & $\begin{array}{l}\text { Possui formação complementar em língua inglesa, } \\
\text { italiano e espanhol. Atualmente, leciona em um colégio } \\
\text { particular de Sinop em ensino bilíngue. }\end{array}$ \\
\hline $\begin{array}{l}\text { Coragem } \\
23 \text { anos }\end{array}$ & Letras/Português-Inglês & $\begin{array}{l}\text { Leciona inglês para crianças desde o } 1^{\circ} \text { período da } \\
\text { Educação Infantil até o } 5^{\circ} \text { ano do Ensino Fundamental I. } \\
\text { Exerce a função de professora de língua inglesa para } \\
\text { crianças há } 1 \text { ano, desde julho de } 2019 \text {, em contexto de } \\
\text { escola privada. }\end{array}$ \\
\hline
\end{tabular}

Fonte: As autoras (2020).

\subsection{Instrumento de produção e procedimentos de análise de dados}

A produção dos dados adveio da realização de entrevistas semiestruturadas, que, de acordo com Gil (2008, p. 109), é "uma das técnicas de coleta dados mais utilizada nas ciências sociais, [...] em que o investigador se apresenta frente ao investigado e the formula perguntas, com o objetivo de obtenção dos dados que interessam à investigação". Nesse sentido, a entrevista permite uma interação social entre pesquisador e entrevistado e possibilita a compreensão dos fenômenos sociais.
As entrevistas aconteceram no segundo semestre de 2020 , em períodos e momentos nos quais as docentes estavam disponíveis. É importante ressaltar que devido ao distanciamento e o isolamento social, as entrevistas tiveram que ocorrer via Whatsapp, como auxílio de um roteiro com tópicos, tais como: contato inicial, tecnologias digitais na formação docente e desafios do ensino remoto.

Após realizadas as entrevistas, o passo seguinte foi ouvi-las novamente, transcrevê-las na íntegra e enumerá-las. Com o auxílio de ferramentas do Word que deixam o texto colorido, foram grifados com cores iguais os dizeres que se sobressaíam, as contradições e aspectos inesperados nas falas das 
professoras. A maioria das respostas foi bem completa e detalhada, inclusive, percebeu-se alguns links com outras questões que contribuíram ricamente para a discussão.

O passo subsequente após a produção dos dados, foi mergulhar sobre eles e organizar as categorias de análise, para, em seguida, analisá-los e interpretá-los pelo olhar das professoras. As categorias foram criadas a partir do aporte teórico que deu suporte a pesquisa, além da pergunta que a direcionou. Cada tópico da análise dialogou com um ou mais aspectos das perguntas da entrevista, com a fundamentação teórica, bem como os objetivos.

\section{Práticas formativas realizadas pelas} professoras de LAC para o uso das tecnologias digitais em sala de aula

Essa primeira parte da análise de dados objetivou responder as dificuldades em relação ao uso das tecnologias digitais pelas professoras. De modo geral, é possível inferir que as professoras não tiveram em sua formação inicial um viés para o uso das tecnologias digitais em sala de aula. Três professoras são formadas há mais tempo, inclusive, Superação saiu da faculdade no ano de 1988 quando a internet chegava ao Brasil. Assim, o conhecimento que têm sobre esse aspecto adveio de uma formação autônoma ou "na marra", como afirma Persistência. Outras continuaram seus estudos após a graduação. Afeto fez uma especialização há alguns anos, cujo trabalho final era nessa área, de tecnologias para o ensino de LI. Calma afirmou que foi na especialização em LAC, através de uma disciplina chamada Tecnologias digitais no ensino de línguas adicionais para crianças, que teve contato com uma formação mais sistematizada sobre a temática, mas também o que sabe vem muito de sua curiosidade e necessidade em se qualificar.

Essas experiências não diferem muito das vivenciadas por Coragem, a professora mais recentemente formada. Discorreu que todo 0 conhecimento que adquiriu sobre as tecnologias digitais vem das suas práticas do cotidiano, "uma formação própria mais empírica”. (CORAGEM, 2020).

Ressalta-se que as docentes entrevistadas atuam em diferentes contextos de ensino, com turmas diversas. Quando perguntadas sobre como foi e é a formação para o uso das tecnologias digitais para atender essa demanda do ensino remoto:

(01) [...] Nós tivemos sim pela prefeitura, a secretaria de educação fez formação através de lives com o setor de tecnologia da prefeitura, eles nos ensinaram a criar o Google Forms, a usar vídeos e nós temos, constantemente, formação nessa área de tecnologia aqui pela prefeitura, mas eu também fiz cursos paralelos, porque a minha deficiência era muito grande, minha limitação era muito grande, então eu precisei correr atrás. Eu estou conseguindo, não é muito fácil, confesso, mas eu estou conseguindo usar muitos recursos. (Superação, ent. $01-08 / 07 / 20)$.

(02) [...] alguém da escola nos apresentou o Zoom, mais ou menos como funcionava e já começamos a usar. O Google Meet foi da mesma forma, alguém criou a conta para nós, nos explicou como iria funcionar e já começamos a usar. (Persistência, ent. $02-10)$

Tabela 2 - Plataformas e materiais digitais utilizados pelas professoras de LAC

\begin{tabular}{lll}
\hline $\begin{array}{l}\text { Plataformas/Aplicativos } \\
\text { digitais }\end{array}$ & $\begin{array}{l}\text { Materiais } \\
\text { digitais/ on- } \\
\text { lines }\end{array}$ & Ferramentas \\
\hline Google Meet & $\begin{array}{l}\text { Livros didáticos } \\
\text { digitais }\end{array}$ & Celular \\
\hline Zoom & Jogos on-line & Computador \\
\hline Google Classroom & Músicas & \\
\hline Power Point & $\begin{array}{l}\text { Vídeos } \\
\text { YouTube do }\end{array}$ \\
\hline WhatsApp & $\begin{array}{l}\text { Lousa on-line } \\
\text { digital }\end{array}$ & \\
\hline YouTube & $\begin{array}{l}\text { Livro digital de } \\
\text { receitas } \\
\text { família }\end{array}$ & \\
& \multicolumn{2}{l}{ de } \\
\hline Facebook &
\end{tabular}

Sites especializados (Canva)

Google Forms

Google (para pesquisa)

Whiteboard

Fonte: as autoras (2020).

O Google Meet foi da mesma forma, alguém criou a conta para nós, nos explicou como iria funcionar e já começamos a usar. (Persistência, ent. $02-10 / 07 / 20)$. 
(03) [...] No caso, foi basicamente aprendendo sozinha, né? Mexendo nos aplicativos e recursos, buscando informações na internet, e com os colegas professores, né? (Calma, ent. $04-12 / 07 / 20)$.

Os dados dialogam com Dias e Pinto (2020), sobre a questão das instituições não terem tempo hábil para formar os professores para atuarem frente a esse contexto de ensino remoto, é tudo muito na prática mesmo, com pressa para acontecer.

A professora Afeto atua em contexto de curso de idiomas e não teve, em sua instituição, formação para esse momento de pandemia. Pontuou que antes mesmo desse momento turbulento, com o advento da globalização, já indicava que os professores precisavam usar as tecnologias digitais até mesmo nas aulas presenciais, pois os alunos têm contato com elas cotidianamente, faz parte do contexto deles.

(04) [...] mesmo antes da pandemia a gente já, nós professores sabíamos que tudo estava apontando para essa direção, depois desse grande evento da globalização muitas coisas mudaram, a gente sabe que a gente precisa usar a tecnologia mesmo em aulas presenciais para motivar os alunos e também nos atualizarmos e estarmos mais dentro do que faz parte do dia a dia deles, principalmente eles, como nativos digitais, a tecnologia é algo muito natural pra eles...(Afeto, ent. 03 10/07/20).

Com relação às as plataformas/aplicativos, materiais e ferramentas digitais que mais usaram em suas aulas, as professoras relataram que tiveram muitas dificuldades em usar esses aparatos e aprenderam a lidar com eles na prática mesmo. Expões, se, por meio de uma tabela, esses aparatos tecnológicos digitais.

Por meio dos dados, pode-se notar que 0 contexto público, apesar de todas as problemáticas, ao qual a professora Superação faz parte, foi o que mais deu suporte aos professores, tendo em vista que ofertou uma formação com o intuito de auxiliar os profissionais na migração da sala de aula física para a virtual. Afirmou ter uma limitação nessa área e buscou outras formas de formação. Persistência cita que "alguém da escola" apresentou os aplicativos, mas não dá para saber se houve uma formação mais direcionada. Coragem e Afeto, pertencentes ao contexto de escola particular regular de ensino, disseram que tiveram de pesquisar formas para ministrar suas aulas, mas afirmaram, também, que suas instituições deram subsídios.

Em virtude dos fatos mencionados, entendese que a falta de uma formação inicial, que tenha como foco a apropriação do letramento digital (LANKSHEAR; KNOBEL, 2008), pode acarretar em problemáticas nas práticas docentes, tendo em vista que a escola é o reflexo da sociedade que tem se transformado de forma cada vez mais rápida. É um processo que ocorre de forma natural, mas teve um aceleramento devido à COVID-19.

Essa formação é necessária para que o professor conheça criticamente as potencialidades ou não de ferramentas digitais que sejam adequadas ao seu contexto de atuação (KENSKI, 1998) e não somente uma formação para o uso pedagógico do computador, mas que sejam possíveis reflexões durante e sobre a prática.

Assim, faz-se necessárias propostas de formação das tecnologias digitais no ensino e aprendizagem de LAC, principalmente, em advento do ensino remoto. As instituições, sejam elas privadas ou públicas precisam assumir essa/e responsabilidade/compromisso, pois não cabe somente aos professores darem conta da problemática com recursos que, muitas vezes, nem dispõem. (MENDONÇA, 2020).

\section{Materiais pedagógicos utilizados pelas professoras de LAC e seus desafios em contexto pandêmico}

Essa segunda parte da análise de dados buscou a mapear quais materiais são utilizados pelas professoras nessa nova realidade, tendo em vista que exige uma adequação ao que se vivencia atualmente.

As professoras relataram vários desafios e dificuldades pelas quais têm passado durante esse momento de distanciamento social em que foi necessária a inserção do ensino remoto na educação. Apesar de pontuarem que sentiram dificuldades em usar e adequar-se às ferramentas digitais, pois, conforme Coragem, era um novo conceito de aula que nunca tinha feito ou experimentado, tinha que estar 
atenta a câmera, som, microfone e muitas outras coisas. O maior problema diz respeito a instabilidade do sinal da internet e até mesmo a falta dela por parte de muitos alunos.

Quando as aulas eram síncronas, via Google Meet ou Zoom, as professoras tiveram que parar diversas vezes e perguntar se as crianças estavam lá, se estavam ouvindo bem. Persistência discorreu que a comunicação era interrompida e não conseguia ouvir o que os alunos falavam e vice-versa.

(05) [...] A comunicação, muitas vezes, não foi perfeita, como por exemplo: os alunos ficavam tendo problemas para me escutar, em que ficavam falando "teacher, não estou escutando, não estou entendendo, teacher minha internet não está boa" [...]. (Persistência, ent. 02 - 10/07/20).

A falta da internet impossibilitou dois alunos da escola de idiomas, na qual Afeto leciona e coordena, acompanhar as aulas. Superação elucidou, em sua fala, que a pandemia escancarou mais ainda as desigualdades sociais que já existiam entre os alunos, haja vista que os que não tinham os aparatos tecnológicos necessários, foram obrigados a realizar as atividades de forma impressa, não tendo como trabalhar a oralidade, uma habilidade essencial, segundo a professora.

(06) [...] alunos que não têm uma internet de qualidade em casa, alunos que não conseguiam continuar o curso, são poucos, no meu caso, que é escola privada, eles têm uma condição melhor, mas houve dois alunos que ficaram impedidos de ver as aulas por causa de qualidade de internet e outros porque não tinham, parece que um deles, não tinha tecnologia adequada para fazer a aula [...]. (Afeto, ent. 03 10/07/20).

(07) [...] imagina que a gente tá trabalhando LI, eu preciso trabalhar a oralidade, 0 aluno que leva atividade impressa, ele perdeu esse quesito oralidade. (Superação, ent. 01 08/07/20).

Diferentemente das outras instituições as quais atuam as outras quatro docentes, que são todas particulares, Superação está vinculada a uma escola pública que não trabalhou e no momento da coleta de dados ainda não estava trabalhando com aulas síncronas. Essa é uma problemática muito séria, enquanto alguns têm acesso à internet e a outros instrumentos necessários para acompanhar as atividades escolares, uma grande parcela é excluída e fica com a aprendizagem comprometida. Este caso é abordado por Liberalli (2020), em que discorre que a dificuldade do acesso à internet, em casos de crianças de comunidades mais pobres, impossibilita a realização das propostas exigidas pelos governos.

Há três formas pelas quais os alunos de Superação podem acessar as aulas e as atividades: a primeira delas é por meio de videoaulas do canal no Youtube criado pela professora em que ela afirma que "[...] isso é um monólogo, porque eu falo, mas eu não escuto [...]"; a segunda via, formulários Google Forms e, a terceira, por intermédio de atividades impressas em que os responsáveis dos alunos se dirigem à escola para retirá-las, em razão de apenas cerca de $30 \%$ dos alunos têm acesso à internet.

De acordo com a professora, aulas nesses formatos não possibilitam uma aprendizagem significativa, tendo em vista que não promovem interação social, este dado condiz com os autores (CARVALHO, 2005; VYGOTKSY, 2007), ao afirmarem que este aspecto é fundamental para o desenvolvimento das crianças e pode promover uma interação maior com a língua a ser ensinada. Nesse sentido, o dado aponta sobre a importância da interação professor e os pequenos aprendizes que ocorre nas salas de aulas físicas, visto que possibilita ver se a criança conseguiu entender o que a ela foi passado e a partir daí realizar suas contribuições no processo de aprendizagem do aluno. Pontua ainda, que a educação nunca foi tão excludente, tendo em vista que a aprendizagem de seus alunos se encontra prejudicada e as lacunas apresentadas, possivelmente, não serão preenchidas.

(08) Em termos pedagógicos é um desafio muito grande você atingir as crianças com coisas significativas, porque as crianças estão em casa, você não tá olhando nos olhos delas, em sala de aula você olha e você percebe quando você tá conseguindo que as 
crianças entendam [...]. (Superação, ent. $01-08 / 07 / 20$ ).

Para trabalhar de forma significativa, a professora procurou partir do ambiente em que os alunos estão para ensinar, relatou que se ia ensinar, por exemplo, cores, solicitava que saíssem pela casa e achassem objetos de determinada cor, se era sobre formas, pedia que desenhassem objetos com a forma de triângulo, retângulo, círculo. Assim, trabalharam vocabulário, mas de forma significativa e contextualizada. Outrossim, percebe-se, à luz deste dado, a relevância de um planejamento significativo das aulas de LAC, conforme Dallagnol (2019), refletir sobre a ambientação, atividades a serem desenvolvidas, possibilita momentos de aprendizagens efetivas.

A importância da aprendizagem, nessa perspectiva, foi também pontuada pelas docentes, mas que fica difícil, porque em alguns momentos a criança não entende bem como realizar as atividades e a professora não tem como saber no momento que está lecionando, principalmente quando são muito pequenas. Assim, seria necessário serem acompanhadas por um adulto, as atividades devem ser diversificadas, uma vez que esse público dispersa rapidamente, o que se torna desafio nesse momento em que o professor também tem que avaliar essa criança.

Sobre essa questão, de não haver um responsável por acompanhar as crianças nas aulas e nas atividades, Afeto ressalta que um aluno de 5 anos parou o curso devido à falta de concentração na aula on-line. Normalmente, a maioria das crianças nessa idade, não consegue ficar quieta, concentrada em atividades por muito tempo. Duas crianças tiveram que parar o curso, dado que seus pais ou responsáveis não tinham tempo para acompanhá-las durante as aulas síncronas, uma vez que os trabalhos dos pais se intensificaram, também, durante a pandemia.

Outra problemática apontada pelas professoras vinculadas ao contexto de ensino particular, diz respeito à avaliação dos alunos. Os conteúdos e atividades tiveram que ser adaptadas para esse momento, entretanto a forma de avaliar não, tendo em vista que essas instituições têm sistemas próprios para fechamento de notas. Nesse quesito, compreende-se que a realização dos momentos avaliativos na perspectiva tradicional, como afirma Santos (2009), não possibilita visualizar se os pequenos aprendizes de língua, realmente, aprenderam os conteúdos abordados.

Em concomitância, as fotos das atividades realizadas por alguns alunos e enviadas às professoras são trêmulas, desfocadas e quase ilegíveis, o que dificulta mais ainda essa questão da avaliação. Muitas vezes têm que entrar em contato com os responsáveis do aluno e pedir uma nova foto. Ao fazerem isso, são até tratadas com ociosidade por alguns pais, quando as responderam. Foi tão trabalhoso que Persistência resolveu pedir que as tarefas fossem entregues na própria escola, pois além disso tinha, também, a questão de que alguns alunos diziam ter enviado as atividades, no entanto, não havia as recebidas. Pode-se perceber nos excertos:

(09) [...] infelizmente, a escola está presa a um sistema de que tem de avaliação, o famoso fechamento de bimestre e atividades avaliativas, então essa parte está sendo bem puxada porque você é muito cobrada, recebemos fotos de atividades on-line, corrigir isso por meio on-line está sendo bem delicado, né? A foto vem trêmula e daí não consigo ler as coisas muito bem, às vezes essas fotos vêm cortadas e ainda tem aluno que não te responde, a família não te responde, é meio complicado, né?.(Coragem, ent.05 - 12/08/20).

(10) [...] E, para nós professores foi cansativo, porque tínhamos que decifrar a escrita, pelo fato da foto não estar bem feita, tínhamos que ir procura de tarefas e trabalhos perdidos quando 0 aluno dizia ter enviado $e$, finalmente, quando eu senti que não aguentava mais lê tarefas on-line, eu decidi "regredir" ao método antigo que eles deixassem as tarefas escritas na escola e foi a forma que obtive mais sucesso.(Persistência, ent. 02 10/07/20).

Devido a essa questão de envio de atividades pelo WhatsApp, Superação ressaltou que a todo momento do dia recebia mensagem de alunos e pais, o que revela que os professores enfrentam dentro 
vários desafios, a questão da falta de privacidade. 0 fato de trabalhar em casa e não ter mais horário certo para parar as atividades, tem causado um desgaste não só físico, mas também emocional, pois, conforme Persistência os professores têm desempenhado suas funções duas, três vezes mais do que normalmente desempenham. Esse dado está em uniformidade com o aporte teórico tecido neste texto, no qual Megale e Nunes (2020) apresentam a perspectiva do assédio moral aos docentes nesse período de realocação da sala de aula física ao ambiente virtual, por consequência da pandemia, cujas relutâncias relacionadas ao emocional destes profissionais está a sobrecarga de cobranças acerca da nova realidade das aulas remotas, de forma que a extrema exposição pode acarretar problemas emocionais como a ansiedade, entre outros.

Mediante os dados expostos, foi possível verificar que os desafios que as professoras enfrentaram para ministrar suas aulas em relação às ferramentas digitais e materiais físicos e on-line são muitos, vão desde o acesso à internet, em que alguns puderam realizar suas atividades e não entregam da forma adequada, até o não acesso à internet, em que outros não dispunham e realizaram as atividades de forma assíncrona, ou somente, por atividades impressas.

Nesse quesito, conforme Aquino e Tonelli (2017) e Santos (2009, 2005), uma das inquietações do ensino de LAC é falta de materiais pedagógicos. Assim compreende-se que no panorama geral a respeito da temática a produção dos materiais que atendam realmente às necessidades dos pequenos aprendizes de língua transfigurou-se em um desafio mais latente aos docentes que buscaram suprir essas dificuldades, mas como afirma Liberalli (2020, p. 15) "depende da forma como são acionados e desenvolvidos os patrimônios vivenciais de cada um". São quatro contextos, com realidades que conversam entre si, mas também com muitas diferenças, como se fossem realidades alternativas coexistindo em um mesmo mundo, o que pode-se caracterizar um perfil de "necroeducação" (LIBERALLI, 2020), infelizmente. Apresenta-se uma tabela com a função de sistematizar os materiais físicos e autênticos e as ferramentas usadas pelas professoras para ministrarem suas aulas.

Tabela 03 - Materiais utilizados pelas professoras de LAC

\begin{tabular}{ll}
\hline Materiais físicos e autênticos & Ferramentas \\
\hline Livros didáticos físicos & Celular \\
\hline Jogos e físicos e brincadeiras (caça ao & Computador \\
tesouro, jogo de adivinhar, flash cards, & \\
contação de histórias e fantoches) & \\
\hline Músicas & \\
\hline Videoaulas gravadas & \\
\hline Atividades impressas para os alunos \\
que não têm internet
\end{tabular}

Fonte: As autoras (2020).

\section{Considerações finais}

Reafirma-se que esta pesquisa é de suma importância para o contexto vivenciado na atual conjuntura da Educação, com reflexões e discussões pertinentes para a área de formação docente e ensino e aprendizagem de LAC. Logo, o trabalho exposto propôs socializar os desafios enfrentados por docentes de línguas adicionais para crianças em relação às ferramentas digitais e materiais utilizados em contexto de aulas remotas, durante a pandemia da COVID-19.

No que concerne aos desafios que esses profissionais enfrentaram para ministrar suas aulas quanto ao uso das tecnologias digitais, materiais físicos e on-line são muitos, como: a falta de privacidade, a não colaboração de alguns pais ou responsáveis das crianças na realização dos exercícios, elas são muito pequenas, assim, seria necessário serem ajudadas por um adulto, instabilidade do sinal da internet e até mesmo a falta dela por parte de muitos alunos, a questão da avaliação (no contexto de ensino particular) dos discentes que não sofreu adaptações. Em concordância a questão da avaliação, outra problemática exposta são as fotos das atividades trêmulas e quase ilegíveis.

O conjunto de dados da pesquisa mostra que os desafios postos ao professor nesse momento são muitos, tanto no que diz respeito ao uso das 
tecnologias digitais, quanto à produção de material pedagógico para servir de apoio durante as aulas. A ausência das tecnologias digitais na formação das professoras refletiu em problemas quando precisaram colocar em prática o uso desses aparatos tecnológicos.

Além disso, evidenciou-se que a escola de contexto público foi o que mais deu suporte aos professores, tendo em vista que ofertou uma formação com o intuito de auxiliar os profissionais na migração da sala de aula física para a virtual.

Destarte, a presença das tecnologias digitais na cultura da contemporaneidade é marcante, cria novas possibilidades de expressão e comunicação. E, assim como aprende-se a usar a tecnologia da escrita, também tem-se forças para enfrentar essas situações desafiadoras do ensino remoto e, como docentes persistentes, aprender a lidar com os novos fenômenos decorrentes da pandemia da COVID-19. Outrossim, o trabalho permitiu uma reflexão sobre as dificuldades que as professoras têm passado, em que, sentiram-se desamparadas, cansadas e sem apoio, principalmente no que concerne à formação realizada, muitas vezes, por conta própria, devido à cobrança em desempenharem, a qualquer custo, suas atividades pedagógicas.

\section{REFERÊNCIAS}

ALBUQUERQUE, Vitória França; SANTOS, Leandra Ines Seganfredo Santos. Letramento Crítico: implicações para a formação inicial de professores de língua inglesa. Revista Humanidades e Inovação, v. 7, n. 8, p. 350-363, mai. 2020. Disponível em: https://revista.unitins.br/index.php/humanidadeseinov acao/article/view/1563. Acesso: 07 set. 2020.

ALMEIDA FILHO, José Carlos Paes de. Quatro estações no ensino de línguas. São Paulo: Pontes Editores, 2012.

ALMEIDA FILHO, José Carlos Paes de. Competências de aprendizes e professores de línguas. São Paulo: Pontes Editores, 2014.

AQUINO, Aline Loyola de; TONELLI, Juliana Reichert Assunção. Ensino de língua inglesa para crianças: Um olhar sobre o desenvolvimento de atividades. REVELLI, v. 9, n. 4, p. 58-76, dez. 2017. Disponível em:

https://www.revista.ueg.br/index.php/revelli/article/vie w/6746/5204. Acesso: 07 set. 2020.
ARAGÃO, Rodrigo Camargo; CAJAZEIRA, Roselma Vieira. Emoções, crenças e identidades na formação de professores de inglês. Caminhos em Linguística Aplicada, v. 16, n. 2, p. 109-133, jan./jul. 2017. BARCELOS, Ana Maria Ferreira; SILVA, Denize Dinamarque da. Crenças e emoções de professores em pré-serviço. Revista Contexturas, n. 24, p. 6-19, mai. 2015.

BAUER, Martin W.; GASKELL, George; ALLUM, Nicholas C. Qualidade, quantidade e interesses do conhecimento: evitando confusões. In: BAUER, Martin W.; GASKELL, George. (org.). Pesquisa qualitativa com texto, imagem e som. Tradução de Pedrinho A. Guareschi. Petrópolis, RJ: Vozes, 2002. p. 17-36.

BRASIL. Portaria № 343, de 17 de março de 2020. Institui o código civil. Diário Oficial da União: seção 1, Brasília, DF, 2020, p. 39, 17 mar. 2020. Disponível em: https://www.in.gov.br/en/web/dou/-/portaria-n343-de-17-de-marco-de-2020-248564376. Acesso: 04 mar. 2020.

CARVALHO, Rosita Edler. Educação Inclusiva: com os pingos nos is. 3. ed. Porto Alegre: Mediação, 2005.

DALLAGNOL, Riscieli. Formação docente: ensinoaprendizagem de línguas adicionais para crianças. 2019. 80 f. Trabalho de Conclusão de Curso. UNEMAT - Universidade do Estado de Mato Grosso. Campus Universitário de Sinop.

DIAS, Érika; PINTO, Fátima Cunha Pereira. Educação e a Covid-19. Ensaio: aval. pol. públ. Educ., Rio de Janeiro, v. 28, n. 108, p. 545-554, jul./set. 2020. Disponível em:

https://www.scielo.br/pdf/ensaio/v28n108/1809-4465ensaio-28-108-0545.pdf. Acesso: 17 set. 2020.

FERREIRA, Magna Maria; ARAUJO, Marcilene de Assis Alves. Impasses na fomação de professores no Brasil. In: COSTA, Rosemeire P. Granada; MENDES, Maria Elaine; ARAUJO, Marcilene Assis Alves (org.). Diálogos entre Letras: propostas de ensino, linguística e formação de professores. Campinas, SP: Pontes Editores, 2015.

FIGUEIREDO, Francisco José Quaresma de. Vygotsky: a interação no ensino/aprendizagem de línguas. São Paulo: Parábola, 2019.

FRIZON, Vanessa; LAZZARI, Marcia De Bona; SCWABENLAND; Flavia Peruzzo; TIBOLLA, Flavia Rosane Camillo. A formação de professores e as tecnologias digitais. EDUCERE - XII Congresso Nacional de Educação, PUCPR, 2015. Disponível em: https://educere.bruc.com.br/arquivo/pdf2015/22806_1 1114.pdf. Acesso: 28 set. 2020.

GIL, Antônio Carlos. Métodos e técnicas de pesquisa social. 6. ed. São Paulo: Atlas, 2008.

KENSKI, Vani Moreira. Novas tecnologias: o redimensionamento do espaço e do tempo e os 
impactos no trabalho docente. Revista Brasileira de Educação. n. 08, p. 58 -71 mai/ago. 1998.

LANKSHEAR, Colin; KNOBEL, Michele (ed.). Digital Literacies: concepts, policies and practices. New York: Peter Lang Publishing, 2008.

LIBERALLI, Fernanda Coelho. Construir o inédito viável em meio à crise do coronavírus - Lições que aprendemos, vivemos e propomos. In: LIBERALLI, Fernanda Coelho (org.); et al. Educação em tempos de pandemia: brincando com um mundo possível. Campinas, SP: Pontes Editores, 2020. p. 13-21.

MEGALE, Antonieta; NUNES, Alexandre. O trabalho com o gênero debate - uma proposta de ensino remoto. In: LIBERALI, Fernanda Coelho (org.); et al. Educação em tempos de pandemia: brincando com um mundo possível. Campinas, SP: Pontes Editores, 2020. p. 171-180.

MBEMBE, A. Necropolítica. Artes e Ensaios, n. 32, p. 122-151, dez. 2016. Disponível em:

https://www.procomum.org/wp-

content/uploads/2019/04/necropolitica.pdf. Acesso: 01 set. 2020 .

MENDONÇA, Márcia. Tecnologias Digitais e ensino de línguas em tempos de pandemia: desafios e percepções de professores. Multiletramentos e Ensino. 2020. (1h 25m 05s). Disponível em: https://www. youtube.com/watch?v=89IEzUYMPts\&t=1 160s. Acesso: 07 mar. 2020.

SCHLATTER, Margarete; GARCEZ. Pedro. Línguas Adicionais (Espanhol e Inglês). In: Rio Grande do Sul, Secretaria de Estado da Educação, Departamento Pedagógico. (org.). Referencias curriculares do Estado do Rio Grande do Sul: linguagem, códigos e suas tecnologias. Porto Alegre: Secretaria de Estado da Educação, Departamento Pedagógico, v. 1, p. 127-172, 2009.

SANTOS, Leandra Ines Seganfredo. Língua inglesa em anos iniciais do ensino fundamental: fazer pedagógico e formação docente. Tese (doutorado) Universidade Estadual Paulista, IBILCE, São José do Rio Preto, 2009.

SANTOS, Leandra Ines Seganfredo. Crenças acerca da inclusão de Língua inglesa nas séries iniciais: Quanto antes melhor? 2005. 215 f. Dissertação (Mestrado) - Instituto de linguagens da Universidade Federal do Mato Grosso, Cuiabá, MT.

TONELLI, Juliana Reichert Assunção. Histórias infantis no ensino de língua inglesa para crianças. 359 f. Dissertação (Mestrado em Estudos da Linguagem) - Universidade Estadual de Londrina, Paraná, 2005.

VYGOTSKY, Lev Semionovitch. A formação social da mente. São Paulo: Martins Fontes, 2007.
ALBUQUERQUE, Vitória França; DALLAGNOL, Riscieli; SANTOS, Leandra Ines Seganfredo. DESAFIOS NO ENSINO E APRENDIZAGEM DE LÍNGUAS ADICIONAIS PARA CRIANÇAS EM TEMPOS DE COVID-19: vozes de professoras de um contexto mato-grossense. Signo, Santa Cruz do Sul, v. 46, n. 85, p. 97-107, jan. 2021. ISSN 1982-2014. Disponível em: <https://online.unisc.br/seer/index.php/signo/article/vie w/15831>. doi:https://doi.org/10.17058/signo.v46i85.15831. 